\title{
O TEMPO E A MEMÓRIA EM CENA: PENSANDO O PROCESSO DE CRIAÇÃO DO DOCUMENTÁRIO EXPANDIDO CINE RABECA
}

\author{
Marcia Mansur de Oliveira ${ }^{1}$
}

\section{Apresentação}

O documentário expandido Cine Rabeca é uma performance realizada com trilha sonora feita ao vivo feita pelos rabequeiros Luiz Paixão e Renata Rosa, parceiros desde 1998 nas poéticas musicais da região da zona da mata norte de Pernambuco ${ }^{2}$. Os músicos estão no centro do palco, sentados lado a lado em um único banco. Por trás deles, projeta-se um filme sobre suas próprias trajetórias, feito a partir de acervo fílmico produzido entre 1991 e $2009^{3}$. Este movimento do duplo filme-performers cria uma imagem cênica que fornece insights situados no encontro entre a pesquisa de campo e a experimentação artística. Assim, proponho neste trabalho uma abordagem analítica do processo de criação do documentário para pensar sobre como a imagem atua na percepção de vestígios do tempo e na evocação de memórias.

A rabeca, instrumento de Paixão e Rosa, tem origem árabe e foi trazidA pelos primeiros colonizadores portugueses, difundindo-se por todo o Brasil. Em cada região, desenvolveu-se de uma forma muito peculiar em relação ao seu formato, afinação e forma de tocar. Tanto a afinação quanto as dimensões do instrumento não são padronizadas. Luiz Alves Ferreira, conhecido como Luiz Paixão ou Seu Luiz, vem de uma família de célebres rabequeiros da Zona da Mata Norte de Pernambuco e inicia seus estudos de rabeca em casa e nos forrós e cavalos-marinhos. A rabeca é o único instrumento melódico do cavalo-marinho e exige grande habilidade musical dos instrumentistas.

O cavalo-marinho, um dos principais cenários em que se passa Cine Rabeca, tanto na plástica do filme quanto na musicalidade do palco, é um "espaço para a mostra

\footnotetext{
${ }^{1}$ Universidade Estadual de Campinas, Brasil. E-mail: mansur.marcia@gmail.com ORCID id: https://orcid.org/0000-0002-5392-2194

2 O trailer do documentário pode ser assistido em: https://vimeo.com/382114439

3 Na edição final do documentário foram incluídas imagens filmadas em 1991 pelo etnomusicólogo John Murphy, que cedeu gentilmente o uso de imagens feitas durante sua pesquisa de doutorado sobre o cavalo-marinho de Pernambuco. Sobre este trabalho ver MURPHY, 2008.
} 
de competência em música, dança, composição poética e humor" (Murphy, 2008: 138). Chamado pelos participantes de brincadeira ou samba, o cavalo-marinho é, historicamente, uma prática dos trabalhadores rurais com duração aproximada de 6 horas que acontece no período natalino como uma sátira às relações sociais da região, mesclando religiosidade e fazer artístico. "A música é um fator importante para sustentar uma brincadeira de cavalo-marinho durante muitas horas ou uma noite inteira. A música é usada para estruturar o tempo e o sabor da performance" (Ibidem: 105). O gênero mescla influências ibéricas e ameríndias com traços da cultura africana apresentando um conjunto de elos e itinerários históricos, com músicas e cantos que combinam poesia, máscaras, teatro e dança. ${ }^{4}$

Neste exercício de formular antropologicamente o processo de criação de Cine Rabeca, experimento a constituição deste documentário expandido como uma linguagem híbrida entre etnografia e arte. $\mathrm{O}$ termo expandido aqui utilizado refere-se às constantes reinvenções das práticas do filme documentário no contexto artístico e na era digital, como a mescla de vídeo com instalações e performances que utilizam outros espaços físicos de exibição além do cinema para propor uma relação particular da obra com o público. Estas abordagens exploram o espaço fílmico que existe para além do monitor, do filme, da câmera ou da tela, além de oferecerem uma maneira de explorar a noção de tempo a partir do que emerge na relação entre o visível e o imaginado, entre memória e experiência do presente (Marley, 2019; Raczynski, 2013; Rush, 2013).

\section{O documentário sob os olhos das pessoas filmadas}

Aos 50 anos, no final da década de 1990, Luiz Paixão prepara-se para deixar o trabalho na cana-de-açúcar ao se profissionalizar no meio musical, passando a se apresentar em palcos e em festivais nacionais e internacionais. Em 2004, na cidade de Olinda, a musicista e cantora de origem paulistana Renata Rosa produz o primeiro CD de Paixão - de quem é discípula no aprendizado da rabeca, e me convida para fazer um documentário sobre o músico. A partir daí, registro em vídeo, entre os anos de 2004 e 2009, diversas situações vividas com a dupla, com a intenção de produzir um documentário etnográfico de curta metragem sobre a trajetória de vida de Seu Luiz.

\footnotetext{
${ }^{4}$ Ver sobre este assunto, dentre outros: MURPHY, Cavalo-marinho pernambucano, 2008; LINEMBURG, As rabecas brasileiras na obra de Mário de Andrade: uma abordagem prática, 2017. LIMA, Música tradicional e com tradição da rabeca, 2001; PERAZZO DA NÓBREGA, A rabeca no Cavalo Marinho de Bayeux, 2000. GRAMANI, O aprendizado e a prática da rabeca no fandango caiçara: estudo de caso com os rabequistas da família Pereira da comunidade do Ariri, 2009
} 
Nestes anos, filmamos Luiz nos ensaios para a gravação do primeiro CD, na turnê de lançamento na cidade de São Paulo e em shows na cidade de Olinda, em diversos cavalos-marinhos em que Renata Rosa toca também, além de festas de aniversário e entrevistas com sua família, entre outros acontecimentos e paisagens da região.

Porém, o tempo que se passa entre a realização dos registros fílmicos feitos entre 2004 e 2009 e as condições de finalização em 2018 transforma o material filmado em arquivo, conferindo-lhe outros sentidos. Sem players adequados para o visionamento, a digitalização e a finalização do projeto só puderam ser viabilizadas mais de uma década após o término das filmagens ${ }^{5}$. Como foram utilizadas fitas Digital-8 e MiniDV, o material torna-se inacessível logo em seguida, quando as câmeras que operam com estas mídias saem do mercado com a entrada das câmeras digitais que gravam em HD.

Ao retomar o projeto, sinto um impulso de fazer este filme com a colaboração dos artistas e o material transforma-se então em um instrumento tanto para nossa reaproximação como para a criação compartilhada que empreendemos juntos a partir dali. Em que momento da vida estariam agora Luiz e Renata? Como seria para eles assistir àquelas imagens que nunca tinham visto? Quais memórias lhes trariam e como poderíamos incorporar essas emoções na peça final a ser editada? Como jogar luz sobre a anacronia do acervo, sobre a relação entre o tempo e o filme documentário?
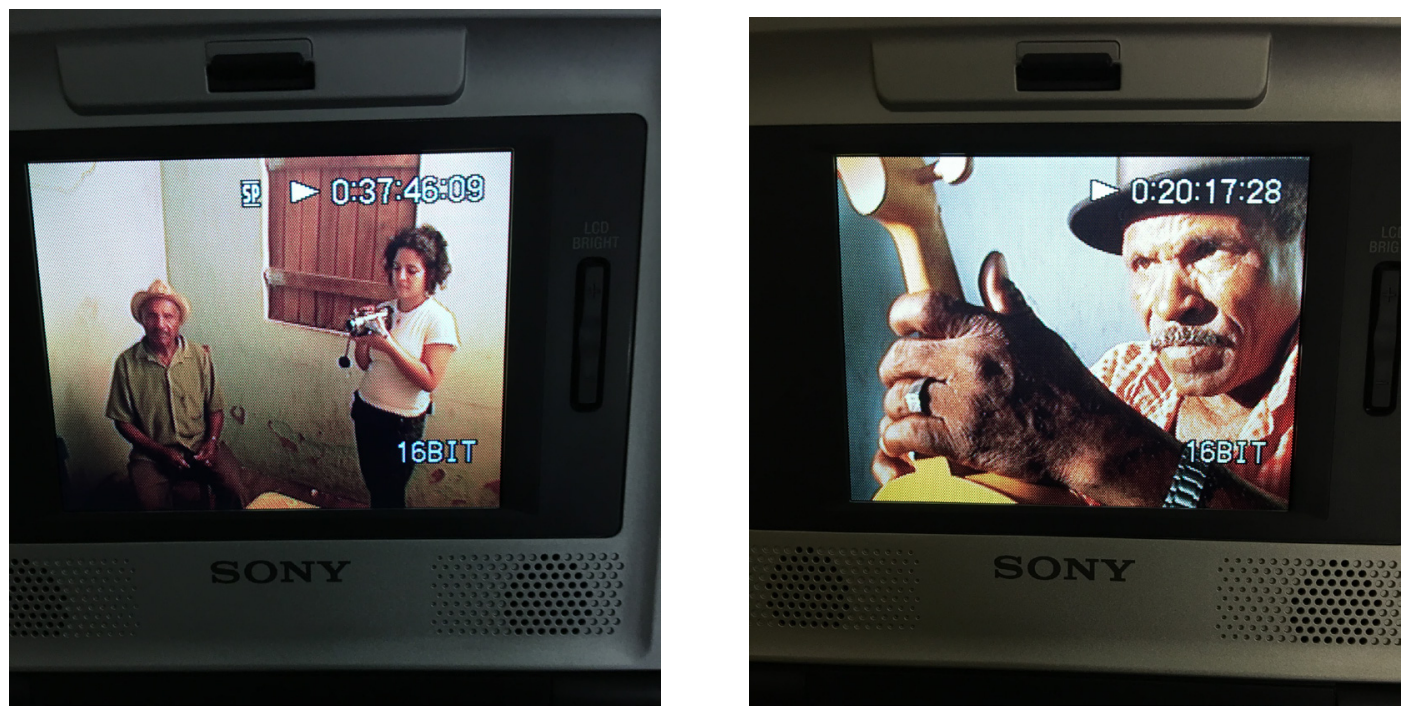

Figuras 1e 2. Vestígios da memória. Fotos: Marcia Mansur (prints do visionamento).

\footnotetext{
${ }^{5}$ A digitalização teve o apoio do Laboratório de Imagem e Som em Antropologia da Universidade de São Paulo (LISA-USP). Em 2018, no âmbito da residência artística do Núcleo de Estudos Contemporâneos do Museu da Imagem e do Som de São Paulo "destinada à pesquisa na área de humanidades, aplicada a produtos de mídias audiovisuais", desenvolvo o projeto que irá resultar no Cine Rabeca. Mais informações em: https://www.mis-sp.org.br/programacao/2263/convocatoria-residencia-necmis-2018.
} 
Reencontramo-nos em abril de 2018, para uma sessão de visionamento de um extenso material bruto já pré-selecionado. As imagens nos despertam emoções que, provavelmente, dizem respeito tanto ao material filmado quanto ao tempo que transcorreu depois das filmagens. Agora estamos muito distantes de 2004 e todos somos espectadores, a documentarista está sob os olhos das pessoas filmadas; não estamos separados pelos dois lados da câmera. Embarcamos na ideia de fazermos um projeto conjunto em que Paixão e Rosa estivessem em cena dialogando musicalmente com o filme, adicionando mais uma dimensão ao espaço fílmico. Seis meses depois compartilho uma pré-edição do material e peço que criem a trilha sonora sobre o ruído do ambiente das ruas, das festas, dos terreiros, da afinação da rabeca, e também sobre o silêncio. Nas apresentações de Cine Rabeca, Luiz Paixão e Renata Rosa estão permanentemente em cena, assistindo ao filme e sonorizando-o até que narrativa fílmica e música ao vivo se confundam em uma só experiência. Os músicos em cena dialogam artisticamente com as projeções audiovisuais e com suas próprias trajetórias e memórias.

Som de sinetas de gado, grilos e vento no teatro. Luiz Paixão e Renata Rosa entram no palco, sentam-se no banco central e afinam as rabecas à meia luz enquanto a tela por trás deles ilumina-se com o início do filme.

Em um travelling lateral, Luiz atravessa de bicicleta a cidade de Condado, Pernambuco. À medida em que Luiz anda, a paisagem urbana vai paulatinamente transformando-se em zona rural, cada vez mais verde. Uma mulher carrega um feixe de lenha, crianças andam de bicicleta em chão de terra batida. Ouvimos Luiz contar em off:

Quando eu nasci foi na luz do candeeiro. Lá não tinha energia. Meu pai foi buscar a parteira, quando ele chegou com a parteira eu já tinha nascido e tava dando cada grito danado. Era brabo que só a peste. De 1949 até chegar 25 anos de idade eu vivia no Engenho Palmeira. Engenho Palmeira fica aqui... Aqui em Condado, a gente passa Limeirinha, Limeira Grande, de extrema Limeira Grande é Palmeira, Engenho Palmeira. Quando foi com 8 anos 
comecei a cortar cana. Cortando cana, limpando mato. E tem serviço mais pesado que aquilo? Tem mais pesado que a cana-de-açúcar? Pra plantar e colher ela... Com 8 anos ia pro serviço cortar cana com o pai. Agora a gente vê um montão de homem tudo novo, sem ter trabalho, porque não tem. Nem corte de cana mesmo agora não tem.

Eu sei que... eu nasci no meio da rabeca, né? Eu comecei a tocar sozinho, fazendo isso sozinho.

No palco, Luiz e Renata que até então estão assistindo ao filme, empunham suas rabecas e começam a tocar um baião de forró, ritmo típico da região. Na tela, trabalhadores colhem e amarram a cana-de-açúcar revelando condições áridas de trabalho que se contrapõem à alegria da música, apresentando a complexidade do cenário em que a história se desenvolve.

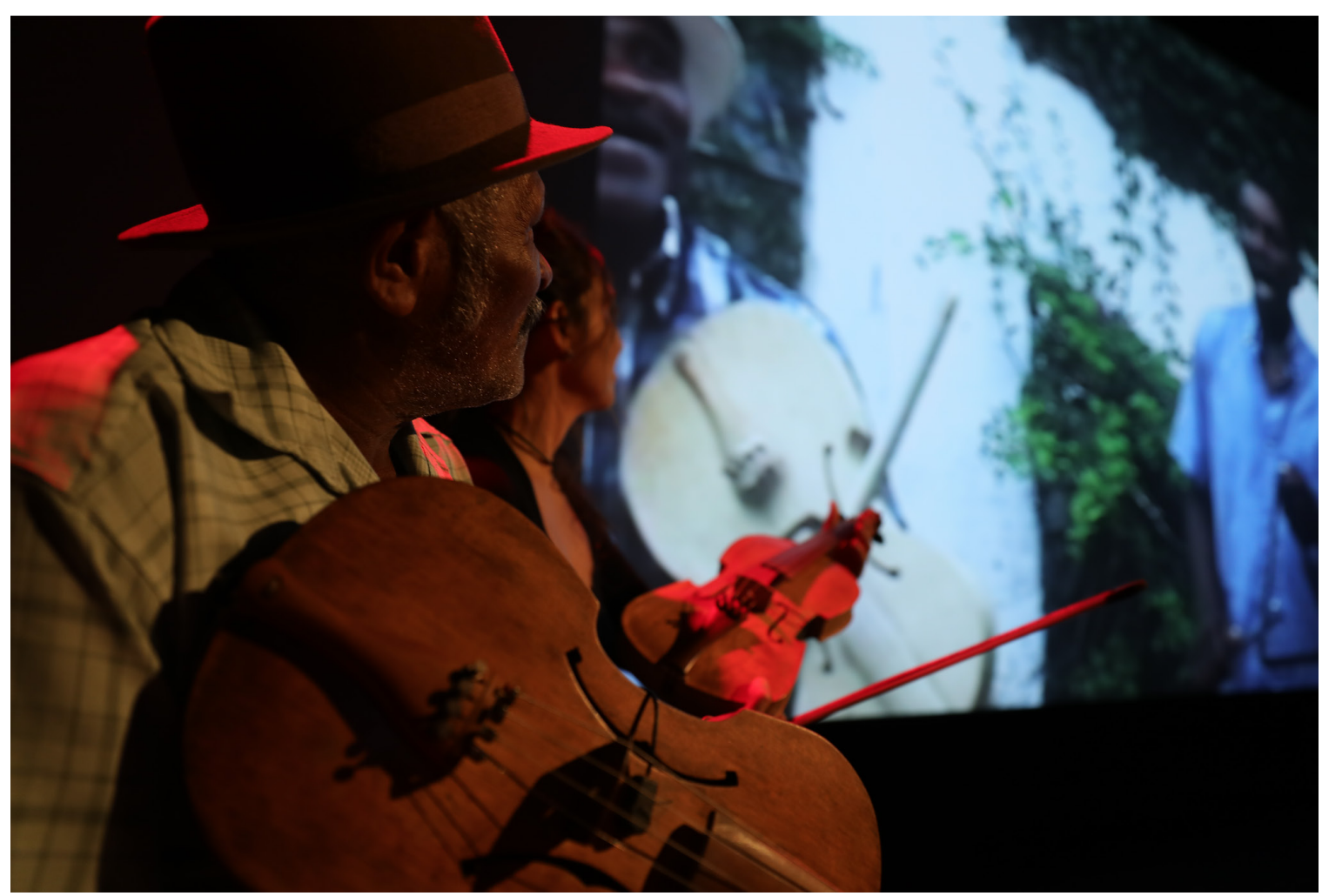

Figura 3. A vida que segue ao filme. Foto: Marina Thomé. 


\section{A travessia do olhar: entre a etnografia e o imaginário}

O antropólogo e cineasta Jean Rouch pensa na câmera como objeto capaz de estimular os seus interlocutores e objetos de pesquisa a entrarem em "performances reveladoras" e que têm o efeito de criar as cenas que filma, de estimular as pessoas a se comportarem de determinada forma e de provocar memórias (Buob, 2017.: 194, apud Desanti \& Decock 1968: 77; Henley, 2009.: 263). Para o processo de construção de Cine Rabeca, buscamos trabalhar com este estímulo cinematográfico para além do momento filmado, preenchendo lacunas da memória através do processo criativo dos personagens sobre o filme editado. De certa forma, ao convidar os personagens do filme para o palco, ampliamos para o campo da experimentação artística os estímulos da memória ao fazer uma releitura sonora e imagética do acervo documental.

Trabalhamos aqui com a ideia de um feedback musical, ou seja, da criação musical a partir dos estímulos provocados pelo filme, dialogando com a metodologia de feedback screenings ${ }^{6}$ implementada por Jean Rouch na produção de filmes etnográficos, e que está na origem da sua proposta de antropologia compartilhada. Na trajetória de Jean Rouch, as sessões de feedback consistem em exibir o material filmado para a comunidade pesquisada, seguido de debates e conversas sobre a abordagem fílmica, que geram uma entendimento mútuo, em que as comunidades compreendem o trabalho do pesquisador ao mesmo tempo em que este apreende suas percepções acerca de temas como imagem, narrativa e dos assuntos específicos que foram registrados. As relações específicas que Rouch estabelece com seus interlocutores ao longo das décadas em que aplica e desenvolve a antropologia compartilhada perpassam uma vasta gama de possibilidades, que vão desde as sessões de feedback até a colaboração em projetos criativos conjuntos, passando pela inserção de narração e comentários das pessoas filmadas na edição final dos documentários, coleta de sugestões de temas relevantes para os próximos filmes, treinamento para que possam atuar como filmmakers em suas comunidades, oportunidades de viagem, etc. (Henley, op.cit: 317-21).

Outra ideia importante para pensar a antropologia compartilhada é o cinetranse, termo cunhado por Rouch por analogia aos fenômenos que filma no continente africano, especialmente na Nigéria. O cine-transe é um conceito que ajuda a transitar entre a etnologia e a poesia, ou entre a antropologia e a arte. É neste estado mental da criação que acessa o imaginário que o pesquisador experimenta o campo enquanto

\footnotetext{
${ }^{6}$ Agradeço à Luisa Godoy Pitanga pela colaboração na identificação do conceito de feedback screenings de Rouch com o projeto Cine Rabeca.
} 
filma, é um meio de percepção sensorial do campo (Buob, op.cit.: 199). Jean Rouch sugere que atuação do filmmaker é uma performance em si mesma e deve estar em uníssono com a performance executada pelos objetos de pesquisa, um estado mental singular de uma certa prática de criação fílmica (Henley, op. cit.: 320). Como diz Marc Piault, no livro Cinema e Antropologia:

O "cine-transe" é um estado que se confunde com o de uma imaginação criadora em ação, estado que é o da produção poética quando ela inventa suas imagens, dando um sentido novo a objetos a partir de então situados em novas relações. (Piault, 2018: 283)

Embora o universo poético do entrelaçamento entre cinema e transe seja considerado por Rouch sobretudo no momento da filmagem, ele é também uma chave para pensar a experiência cinematográfica como um todo (Buob, op. cit.: 186/7). Ciente do desafio, me proponho a trabalhar a experiência sensorial do cine-transe aplicada à criação e apresentação de Cine Rabeca como um exercício de antropologia compartilhada. Em Cine Rabeca, o cine-transe pode estar associado à ideia de travessia, também trabalhada por Jean Rouch (Henley, 2009; Piault, 2018; Hikiji, 2013); este trânsito entre as fronteiras do palco e da tela, um cruzamento entre o documentário e os sujeitos filmados, entre a vida e o filme. Ou seja, além do momento em que filmamos, a travessia do olhar e dos sentidos se dá durante o processo de edição e criação musical e também quando se assiste à performance: são momentos em que as imagens nos interpelam. As imagens filmadas há 15 anos nos conduzem a um tempo que não era acessível de outra forma, o espaço de uma memória compartilhada por mim, que conduzi as equipes de filmagem à época, e por eles, que estavam em frente às câmeras. Tempo e memória articulam-se neste espaço singular em que entramos a partir do dispositivo fílmico, submetendo a experiência etnográfica ao processo artístico, conduzindo-nos à experimentação de uma nova forma de colaboração entre linguagens distintas como música, filme e antropologia. Dessa forma, o cine-transe pode ser mobilizado para relativizar o documentário etnográfico tanto como meio de apreensão da realidade quanto como encontro entre arte e antropologia.

No filme, em entrevista filmada em 2006, Luiz conta como nasceu a inspiração para fazer o forró Pimenta com Pitú, que dá origem ao nome de seu primeiro CD. Ele e os amigos faziam música na sala de sua casa, bebendo aguardente com um tira-gosto à 
base de maxixe, molho de coco, e pimenta - e dali nasceu a música. No palco, Luiz ri ao assistir-se contando sua própria história. Paixão e Rosa executam no palco a composição instrumental Pimenta com Pitú, que demonstra o virtuosismo de seu autor, enquanto o filme mostra cenas de Luiz tocando com amigos e família em diversas situações. A música termina e fotos de arquivo pessoal de Luiz e Renata no final dos anos 1990 tomam a tela. Renata Rosa, em cena, pede a palavra:

Quando eu conheci Seu Luiz eu falei: - Eu quero aprender rabeca com o senhor.

Eu estava encantada com a agilidade, o ritmo, as ornamentações, os fraseados, a musicalidade dele. Ai ele falou: eu moro lá no engenho Gurijó, depois de Itaquitinga, lá na lapa da pedra, se você quiser, pode vir. E foi o começo. Passei muitas temporadas com Seu Luiz em Gurijó, tocando no terreiro, à luz do candeeiro, proseando, batendo aquele engenho todo à pé... Chegou uma hora que Seu Luiz me chamou pra tocar com ele no cavalo-marinho de Biu Roque e ali, a gente selou uma família. Nessa época, eu estava começando meu trabalho solo e chamei Seu Luiz para tocar comigo. Então, eu tocava com ele no cavalomarinho e ele passou a tocar comigo. E a gente vivia nesse circuito: cavalomarinho no interior, ensaios em Olinda e festivais e teatros na Europa.

No palco, Luiz e Renata voltam-se para a tela e conduzem seus olhares para o filme, mergulhando nas lembranças dos ensaios para a gravação do CD no quintal da casa em que Renata vivia à época. Em entrevista filmada em 2004, Luiz explica:

Agora, esse negócio de rabeca, acabou-se. Tem pouco rabequista lá no interior, que eu conheço. E, antigamente, quando eu nasci, tinha muito rabequista. No tempo do meu avô, dos meus tios, aí existia. Todo sábado era baile de rabeca. Mas isso foi antigamente, com o pessoal mais velho. Aí começou essas coisas de discoteca, o povo mudando, e tal. E o povo foi esquecendo da rabeca. Agora, o povo da cidade grande está descobrindo o que é a rabeca. Estão puxando a rabeca de novo. Agora todo mundo quer aprender a tocar rabeca. Eu acho bom todo mundo tocar a rabeca, porque quando os mais velhos vão morrendo, os mais novos vão tocando. Por isso que Renata Rosa aprendeu, um bocado de 
gente. Essa menina vai aprender, você também, se quiser, que não é nada dificil.

É possível que a combinação da performance musical ao vivo com filme de arquivo evidencie efeitos da passagem do tempo esculpidos à apresentação do vídeo, como se os corpos estivessem descolados de suas próprias imagens. Neste deslocamento entre o duplo imagem-performer, cria-se também uma realidade cênica que põe em xeque o documentário como representação da realidade. A travessia do olhar que passeia entre os músicos em cena e o passado fílmico mostra um processo de inacabamento (Piault, op. cit.: 313) que transcende a finalização dos documentários; da própria vida que se segue a um filme que, por sua vez, cristaliza momentos e congela o tempo.

Aqui, o tempo é imaginado, fundamentado na visão, na audição. Nessa interface entre o real e o imaginário, o tempo é uma experiência sensorial, que se sente/imagina e que se apresenta no duplo documentário-realidade, em que a vida se mostra como um nascimento contínuo. Jean Rouch afirma que o ato fílmico é uma via de acesso ao imaginário: enquanto o olho direito está trabalhando no visor da câmera, o olho esquerdo alterna-se entre olhar o que está acontecendo fora do que está sendo enquadrado pela câmera e fecha-se para garantir a melhor fotografia do que está sendo filmado (Buob, op.cit.: 190 apud Rouch 1989b: 182). Nessa transposição entre o olho esquerdo que observa e o olho direito que filma ocorre a criação fílmica e a produção imaginária. Este processo evidencia que o documentário não captura uma verdade única, mas cria em seu enquadramento uma nova realidade, subsumida no tempo do ato fílmico. Esta dimensão do espaço que é deflagrada pela câmera, cuja imagem que produz "é a observação em campo" (Piault, op. cit.: 140), traz a memória do campo para a cena e evidencia o recorte etnográfico.

Vale enfatizar que, para Rouch, o cinema seria a arte do duplo: revela um "tipo de personagem duplo", "o personagem no filme e o personagem fora do filme" (Buob, op. cit.: 208 apud Guillon 1961; Henley, op. cit.: 275). É esta transição do mundo do real para o mundo do imaginário através da criatividade poética cinematográfica que faz aparecer "este duplo, esse eu no outro e esse outro em nós que o antropólogo busca 
fazer dialogar a fim de que eles se encontrem, mas sem se confundirem, sem se devorarem" (Piault, op.cit.: 313).

Assim, a narrativa do espetáculo produzido com os interlocutores de campo articula-se à primeira ruptura epistemológica sobre o uso do filme para a pesquisa de campo, "quando se compreendeu que já não se tratava (...) de decompor e de imobilizar o movimento para melhor compreendê-lo, mas que, ao contrário, havia enfim a possibilidade de chegar a uma prática de duração ao ver o movimento como articulação do tempo e do espaço" (Piault, op. cit.: 142).

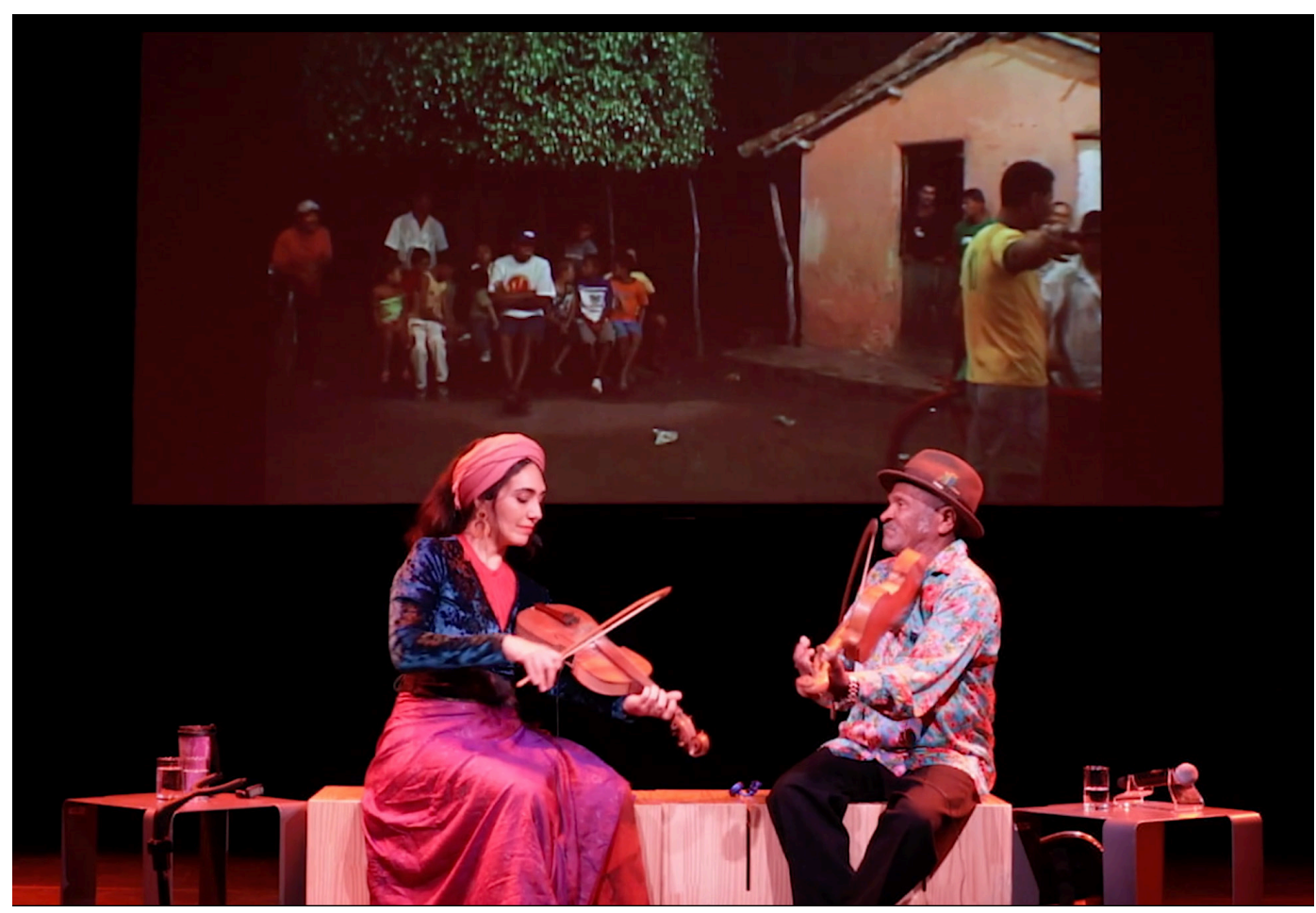

Figura 4. Rastros da imagem etnográfica. Foto: Marina Thomé.

Em Condado, é noite no terreiro da casa em que vive Seu Luiz. No filme, informações em texto informam que, à noite, terá cavalo-marinho em comemoração ao aniversário de Maíca, companheira de Luiz e filha de Biu Roque ${ }^{7}$, o dono do cavalomarinho.

\footnotetext{
7 Biu Roque (1934-2010) é uma grande referência artística para Luiz Paixão e Renata Rosa e para muitos artistas brasileiros, assim como para os cavalos-marinhos da região, além de ter sido amigo e parceiro de Luiz por décadas.
} 
Preparativos para a festa, montagem dos equipamentos de som, dos figurinos. Em um cômodo da casa, Luiz, Renata e Biu Roque trabalham para afinar as rabecas. Biu Roque afinadíssimo em sua poderosa voz aguda, canta uma toada de cavalomarinho para dar o tom para as rabecas. É na voz de Biu Roque que Luiz e Renata afinam suas rabecas para a brincadeira que vai começar.

Enquanto isso, no terreiro do lado de fora, um longo plano observacional fixo enquadra ao fundo uma casa caiada de cor-de-rosa e um pequeno banco de madeira sob uma frondosa árvore, no qual sentam e levantam várias crianças. Em primeiro plano, passantes de bicicleta, preparos para a festa, vizinhos observam o vai e vem.

No palco, entre olhares cúmplices, Luiz e Renata tocam um suave baião de cavalo-marinho anunciando a festa que vai começar.

\section{A memória em cena e os rastros da imagem etnográfica}

Tempo e memória, tanto pessoais quanto artísticos, são a substância da performance Cine Rabeca, que trabalha com a possibilidade de misturar vídeo, som, movimento, execução musical, tempo e memória para criar uma única expressão imagética complexa. A experiência performativa de perscrutar a memória funciona um jogo de espelhos no espaço, alternando-se ora nos terreiros trazidos pelo filme, ora nos palcos, com a imagem da cena. Em cena, como Renata e Luiz tornam-se espectadores de suas próprias memórias e interagem com imagens filmadas de si mesmos projetadas sobre a tela atrás deles, visualizamos "relações temporais em um contexto espacial" (Rush, 2013: 34). Além das imagens projetadas na tela, a cena do documentário expandido produz uma nova imagem, a que engloba Renata Rosa e Luiz Paixão fisicamente no palco. A imagem da cena se forma como um modo de conhecimento do tempo e das relações intersubjetivas. Neste sentido, como diria Roy Wagner,

Dependemos da memória, da expectativa e da aspiração para dar continuidade aos nossos pensamentos e ações, segue-se que vivemos as sequências de nossas vidas antes e adiante de cada momento da época. Cada instante é o começo do passado. Passado e futuro nada são além de imagens... (Wagner, 2017: 118)

Esta imagem da cena compõe o que eu gostaria de chamar aqui de "rastro do acervo audiovisual etnográfico". A imagem, neste sentido, seria algo que condensa domínios de ideias e interpretações e "permite que relações complexas sejam percebidas 
e compreendidas num instante" (Wagner, 2017: 39). Trata-se de uma imagem sinestésica, que cruza sensações e sintetiza significados ambíguos e complementares. De certa forma, o acervo fílmico constituído nesse projeto é a produção de uma antropóloga caçadora-coletora de imagens, que segue e cria rastros e relações. Ao seguir o rastro como um ato criativo, como diria Roy Wagner, a vida "em todos os seus atos, torna-se um processo de inscrição" (Wagner, 2017: 29). No nosso caso, a inscrição dos rastros da vida confunde-se com a de uma época e é revelada tanto na textura das imagens (filmadas em VHS, mini DV e Digital-8) quanto nas condições que possibilitaram criar tal performance. A noção wagneriana de época considera a percepção do tempo como algo "imbuído com a direcionalidade da vida" e, nesta perspectiva, época seria “o tempo considerado orgânico, acontecendo ao mesmo tempo que o enquadramento a partir do qual ele é percebido. (...) Ela é a presença do tempo" (Wagner,

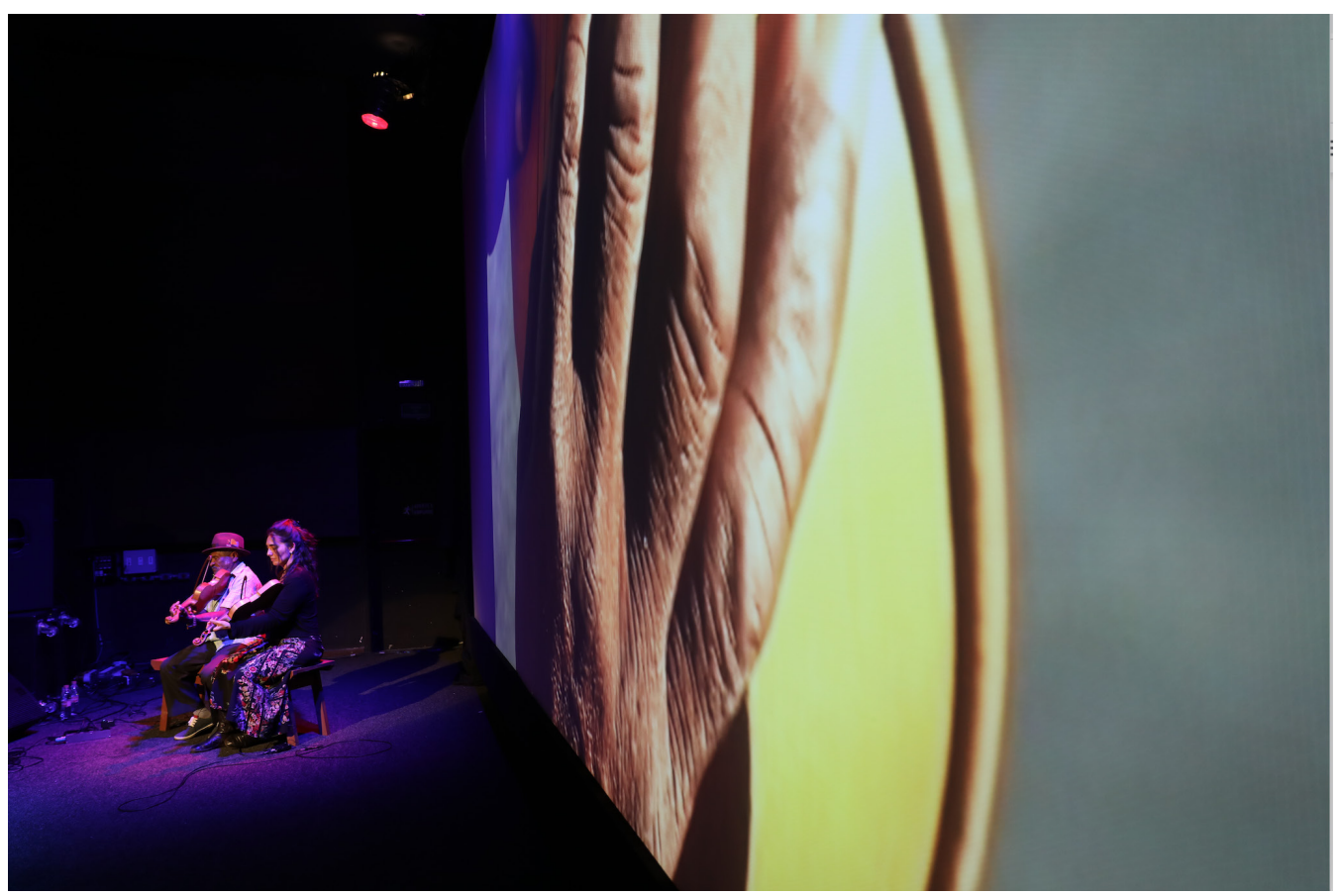

Figura 5. A espessura do tempo. ${ }^{8}$ Foto: Marina Thomé.

Neste sentido, além da passagem do tempo que nitidamente se percebe entre as imagens projetadas e os artistas em cena, a presença do tempo é também manifesta, a um só tempo, neste campo relacional estabelecido entre os músicos, com o vídeo, com o público e com o tempo espacializado no palco. A imagem da cena é a presença do

\footnotetext{
${ }^{8}$ Agradeço a contribuição da Prof. Fabiana Bruno para o título desta foto.
} 
tempo. Nesta resolução, o destino dado ao material fílmico engloba passado e presente em uma articulação temporal, como forma de experimentar o tempo (Wagner, 2017: 117). O tempo entre as filmagens e a edição transformou o documentário em filme de arquivo que por sua vez constitui "uma memória renovada em que a trama dos acontecimentos será abertamente perpassada pela ambiguidade dos sentimentos expressados pelos movimentos, rostos, olhares e, enfim, sons.” (Piault, op. cit.: 371).

É quase como se a distância entre os personagens em cena e a tela atrás deles pudesse ser medida não em metros, mas em tempo, revelando o tempo que se passou; entre a presença dos músicos no palco a as suas próprias imagens de 15 anos anos projetadas. Em cena, Paixão e Rosa recriam pela música, a sociabilidade do cavalomarinho e da zona da mata norte Pernambucana, que se vê no documentário. A narrativa é permeada com a linguagem da memória, que se articula entre vestígios e reminiscências, construindo sentidos. Se o que sobrevive entre épocas são os vestígios, tal sobrevivência é o que "nos permite o acesso a uma materialidade do tempo" (DidiHuberman, 2019: 121), uma vez que a memória causa e opera efeitos de montagens, criando uma sensação de tempo. Assim, "escavar através das espessuras do esquecimento" (Ibidem: 56) é uma forma de montagem com as fronteiras contidas nas imagens. A memória nos permite escapar de uma imagem à outra, caminhar com sucessivos elementos de imagens que criam a ilusão do movimento. Como diz Jaques Rancière, a memória deve "construir-se como uma ligação entre dados, entre testemunhos de fatos e vestígios de ação" (Rancière, 2013: 160).

Nesta mescla de linguagens artísticas, exploramos em Cine Rabeca três camadas de projeção: a memória (o passado do filme), a invenção (o futuro do passado através da recriação musical feita pelos músicos sobre suas experiências prévias) e a cena (o momento presente compartilhado com o público). As apresentações do documentário embaralham as fronteiras entre passado, presente e futuro, em uma montagem de tempos heterogêneos, como diria Didi-Huberman. De certa maneira, nosso processo de montagem dialoga com a percepção histórica das descontinuidades do tempo, na medida em que "os fatos do passado não são mais coisas inertes a serem encontradas, isoladas, em seguida apreendidas numa narrativa causal” (Didi-Huberman, 2019: 116).

Assim, através do processo de pensar questões tratadas pela antropologia ou objetos etnográficos por meio da experiência estética - aquilo que nos é provocado através dos sentidos - percebemos o tempo e a memória materializados em imagens. 
Esta tensão entre a imagem da cena e os elementos que a compõem evidencia a relação "entre um todo e as partes, entre uma visibilidade e uma potência de significação e de afeto que lhe é associada, entre as expectativas e aquilo que vem preenchê-las" (Rancière, 2016: 11/12). A relação de elementos visíveis na imagem da cena é produzida por um encadeamento que articula oposições e continuidades. A alteridade está presente na composição da imagem entre "um sentimento e os tropos de linguagem que o expressam" (Rancière, ibid.: 21). Esta tensão entre o presente e o passado acomoda-se na montagem heterogênea do que acontece entre a tela e o palco.

$\mathrm{Na}$ análise do processo criativo feita neste trabalho, "a ideia de imagem e a matéria imageada" (Rancière, 2013: 170) convivem no encontro entre as experiências etnográfica e artística. A imagem, como dispositivo poético com poder de síntese que provoca múltiplas interpretações de significado, designa tanto o recorte da pesquisa de campo, à semelhança da realidade, quanto a alteração desta matéria na articulação entre o visível e o invisível que se acontece no campo da arte.

Sequência de coloridas imagens de cavalos-marinhos em fusão. Pés ritmados, saias e fitas coloridas girando, máscaras, instrumentos. As imagens em fusão remetem às camadas oníricas da memória, que se experimenta sem fronteiras definidas. Em off, o diálogo final com Biu Roque:

- Porque é que senhor brinca o Cavalo-Marinho?

- Porque eu acho bonito. Bonito demais. Se eu pudesse brincava 7 dias, é porque não posso.

- 8 dias da semana! (provoca alguém que está por perto)

-7 dias dava.

No filme, o raiar do dia anuncia-se marcando o final de uma brincadeira de cavalomarinho ainda em festa. Em cortejo, um grupo leva a alegoria do boi para a carroceria de madeira do veículo em que estão os brincantes que, com arcos de fitas em punho, dançam e despedem-se da câmera, enquanto o caminhão alcança a estrada e a toada continua nos palcos, nas mãos de Luiz e Renata. 


\section{Referências Bibliográficas}

BUOB, Baptiste. Splendeur Et Misère De La Ciné-transe - Jean Rouch Et Les Adaptations Successives D'un Terme “Mystérieux". Éditions de l'EHESS | « L'Homme » 2017/3. Disponível em: https://www.cairn.info/revue-1-homme-2017-3-page-185.htm. Acesso em 28/11/2019.

DIDI-HUBERMAN, Georges. Diante do tempo. História da arte e anacronismo das imagens. Belo Horizonte, Editora UFMG, 2019.

GRAMANI, Daniella da C. O aprendizado e a prática da rabeca no fandango caiçara: estudo de caso com os rabequistas da família Pereira da comunidade do Ariri.

Dissertação de mestrado, UFPR. Curitiba, 2009

HENNESSY, K., FORTIN, C., KADIR, A., MUNTEAN, R., WARD, R. (2015). Producing New Media Ethnographies with a Multi-Sited Approach. ISEA'15: 21st International Symposium for Electronic Arts. Vancouver B.C., 2014

HENLEY, Paul. The Adventure of the Real - Jean Rouch and the Craft of Ethnographic Cinema. Chicago, The University of Chicago Press, 2009.

HIKIJI, Rose Satiko. Rouch compartilhado: premonições e provocações para uma antropologia contemporânea. In: Iluminuras, Porto Alegre, v.14, n.32, p.113-122, jan./jun. 2013.

LINEMBURG, Jorge. As rabecas brasileiras na obra de Mário de Andrade: uma abordagem prática. Florianópolis, Ed. Quebra Ventos, 2017.

LIMA, Agostinho. Música tradicional e com tradição da rabeca. Salvador, Dissertação apresentada ao Programa de Pós-Graduação em Música da UFBA, 2001.

MACDOUGALL, Douglas. The corporeal image. Film, ethnography and the senses. New Jersey, Princeton University Press, 2006.

MARLEY, Keith. Expanded Documentary: The Aesthetics of Pleasure. In: InMedia The French Journal of Media Studies (2019). Disponível em:

https://journals.openedition.org/inmedia/1748. Acesso em 28/01/2020.

MURPHY, John. Cavalo Marinho pernambucano. Belo Horizonte, Editora UFMG, 2008.

NETO, João Nicodemus de Araújo. A construção da rabeca: idiossincrasias do Mestre Antônio Merengue. Dissertação de mestrado, UFPB. João Pessoa, 2016.

PIAULT, Marc. Antropologia \& Cinema. São Paulo, Ed. Unifesp, 2018.

PINK, Sarah. Doing Sensory Ethnography. London, SAGE Publications Ltd, 2009.

Disponível em: http://methods.sagepub.com/book/doing-sensory-ethnography/n2.xml.

Acesso em 8/04/2015. 
PERAZZO DA NÓBREGA, Ana Cristina. A rabeca no Cavalo Marinho de Bayeux, Paraíba João Pessoa, Editora Universitária, 2000.

RACZYNSKI, Anna. The Moving Image: Expanded Documentary Practice in Contemporary Art. In: Sztuka i Dokumentacja, nr 9 (2013). Disponível em: http://www.journal.doc.art.pl/pdf9/anna raczynski mowing image.pdf. Acesso em $30 / 01 / 20$.

RANCIÈRE, Jaques. A fábula cinematográfica. Campinas, Papirus Editora, 2013a. $O$ destino das imagens. Rio de Janeiro, Ed. Contraponto, $2016 \mathrm{~b}$.

ROUCH, Jean. The camera and man. In: Cine-Ethnography: Jean Rouch (FELD, Steven, org.). Minneapolis, University of Minnesota Press, 2003.

RUSH, M. Novas Mídias na Arte Contemporânea. São Paulo, Ed. Martins Fontes, 2013

WAGNER, Roy. Símbolos que representam a si mesmos. São Paulo, Editora Unifesp, 2017.

Recebido: $31 / 01 / 2020$

Aprovado: 15/07/2020 